in vivo 35 : $999-1006(2021)$

doi:10.21873/invivo. 12343

\title{
The Controlling Nutritional Status CONUT Score in Patients With Advanced Bladder Cancer After Radical Cystectomy
}

\author{
YUKI NEMOTO $^{1}$, TSUNENORI KONDO ${ }^{2}$, HIROKI ISHIHARA ${ }^{1}$, TOSHIO TAKAGI ${ }^{1}$, HIRONORI FUKUDA ${ }^{1}$, \\ KAZUHIKO YOSHIDA ${ }^{1}$, JUNPEI IIZUKA ${ }^{1}$, HIDEKI ISHIDA ${ }^{1}$ and KAZUNARI TANABE ${ }^{1}$ \\ ${ }^{1}$ Department of Urology, Tokyo Women's Medical University, Tokyo, Japan; \\ ${ }^{2}$ Department of Urology, Tokyo Women's Medical University Medical Center East, Tokyo, Japan
}

\begin{abstract}
Background/Aim: The impact of the controlling nutritional status (CONUT) score on oncological outcomes after radical cystectomy $(R C)$ for advanced bladder cancer $(B C)$ is unknown. Patients and Methods: We retrospectively evaluated 115 patients who underwent $R C$ for advanced $B C$ at our department between November 2003 and February 2019. The CONUT score was calculated from serum albumin levels, total lymphocyte counts, and total cholesterol levels. Relapse-free survival (RFS), cancer-specific survival (CSS), and overall survival (OS) after RC were analyzed. Results: For the CONUT score, the area under curve was 0.651 and the optimal cut-off value determined using the Youden index was 3. The high CONUT group had significantly shorter RFS, CSS, and OS than the low CONUT group. Multivariate analyses showed that the CONUT score was an independent prognostic factor of RFS, CSS, and OS. Conclusion: The CONUT score could be an effective predictor for survival and tolerability following $R C$ for advanced $B C$.
\end{abstract}

Nutritional status can be impaired by cancer-induced chronic inflammation (1, 2). Accordingly, several systemic inflammatory or nutritional factors have been identified for prediction of patient survival $(3,4)$ and tolerability of surgery $(5,6)$ or systemic chemotherapy (7) in various types of cancer. In this context, the controlling nutritional status (CONUT) score, which consists of serum albumin levels, total lymphocyte counts, and total cholesterol levels, has been

This article is freely accessible online.

Correspondence to: Tsunenori Kondo (ORCID iD: 0000-00025146-656X), MD, Ph.D., Department of Urology, Tokyo Women's Medical University Medical Center East, 2-1-10 Nishiogu, Arakawa-ku, Tokyo 116-8567, Japan. Tel: +81 338101111, Fax: +81 358556319, e-mail: kondo.tsunenori@twmu.ac.jp

Key Words: Urothelial carcinoma, inflammation, predictor, sarcopenia, cachexia. reported to be a useful predictor of survival in gastrointestinal cancer (8). The CONUT score has also been reported to be associated with prognosis in other types of cancers including renal cell carcinoma (9) and lung adenocarcinoma (10). These findings suggest that the CONUT score may be utilized for outcome prediction regardless of cancer types.

Bladder cancer (BC) is the second most common urologic cancer, and $25 \%-30 \%$ of cases present with advanced disease (11). For these cases, radical cystectomy (RC) is the standard treatment, but the postoperative prognosis and surgical complications remain problematic $(12,13)$. Therefore, effective predictors for outcome prediction following RC for advanced $\mathrm{BC}$ are needed. Several studies have suggested that nutrition and inflammatory factors, such as the modified Glasgow Prognostic Score, sarcopenia, and prognostic nutritional index, might be useful as predictive factors of prognosis in BC (1416). Furthermore, we have previously reported that sarcopenia and the CONUT score were significantly associated with survival following radical nephroureterectomy in patients with upper tract urothelial carcinoma $(17,18)$.

This study aimed to evaluate the association between the CONUT score and postoperative outcomes including survival and tolerability following RC in advanced BC. We hypothesized that the CONUT score is associated with oncological outcomes in patients with advanced BC undergoing $\mathrm{RC}$ and can thus be used as an effective prognostic factor.

\section{Patients and Methods}

Study design and patients. This retrospective study was approved by the internal Ethics Review Board of Tokyo Women's Medical University (ID: 5329) and was performed in accordance with the principles outlined in the Declaration of Helsinki.

The subjects were patients who underwent RC for advanced BC without distal organ metastases (i.e., cM0) at our department between November 2003 and February 2019. Of the 171 patients identified, we excluded 56 patients who had undergone maintenance dialysis $(n=14)$, who had undergone prior radical nephroureterectomy for upper tract urothelial carcinoma $(\mathrm{n}=15)$, and whose clinical data before and after 
$\mathrm{RC}$ were missing $(\mathrm{n}=27)$. Finally, 115 patients were evaluated in this retrospective study. The patients were classified into two groups based on the cutoff CONUT score determined using the receiver operating characteristic (ROC) curve and the Youden index (19). The oncological outcomes including survival after RC and the rate and grade of postoperative complications were compared between the two groups. Risk factors for survival were also investigated.

Clinical and laboratory data were extracted from the electronic database and patients' medical records. Tumor staging was according to Union for International Cancer Control TNM classification (20). The preoperative stage was determined based on findings from imaging examinations including computed tomography or magnetic resonance imaging.

Calculation of the CONUT score. The CONUT score was calculated from the serum albumin levels, total lymphocyte counts, and total cholesterol levels, as previously described (21) (Table I). We evaluated the CONUT score using peripheral blood samples obtained within 1 month before the RC in routine clinical practice.

Evaluation of oncological outcomes. The survival impact of the CONUT score was evaluated according to relapse-free survival (RFS), cancer-specific survival (CSS), and overall survival (OS) after RC. Meanwhile, the impact of the CONUT score on tolerability to RC was evaluated according to the incidence rate and grade of postoperative complications and the duration of postoperative hospitalization after RC. Only postoperative complications that developed within 3 months after RC were analyzed, and their grades were also assessed based on the ClavienDindo classification (22).

Neoadjuvant chemotherapy. Neoadjuvant chemotherapy was considered when there was adequate time to conduct $\mathrm{RC}$ or when an anti-tumor benefit was expected for advanced BC, with careful consideration of the patients' comorbidities, performance status, and willingness to undergo chemotherapy. The regimen generally consisted of cisplatin-based chemotherapy including 1-4 cycles of gemcitabine plus cisplatin or carboplatin or 1-2 cycles of methotrexate, vinblastine, adriamycin, plus cisplatin.

Statistical analysis. Continuous variables were analyzed using the Mann-Whitney $U$-test, whereas categorical variables were analyzed using the $\chi^{2}$ test. RFS was defined as the time from RC to the first local recurrence, metastasis to distal organs, or any-cause death. CSS and OS were defined as the time from RC to cancer-related death and any-cause death, respectively. All survival outcomes were calculated using the Kaplan-Meier method and compared using the log-rank test. To identify risk factors of survival after RC, multivariate analyses for RFS, CSS, and OS were performed using the Cox proportional hazards regression models. Risk was expressed as the hazard ratio (HR) with $95 \%$ confidence interval (CI). All analyses were preformed using the JMP software (version 15; SAS Institute Inc., Cary, NC, USA), and differences with a $p$ value of $<0.05$ were considered statistically significant.

\section{Results}

Patients' characteristics. The ROC analysis for the CONUT score showed that the area under curve predicting CSS was 0.65 (Figure 1). According to the maximum Youden index method, the cut-off of CONUT score was determined at 3 . Based on this cut-off value, 22 patients (19.1\%) were classified into the high CONUT group (i.e., CONUT score $\geq 3$ ), whereas 93 patients $(80.9 \%)$ were classified into the low CONUT group (i.e., <3). The specific scores of the individual factors of the CONUT score of the two groups are shown in Table II.

The patients' characteristics are summarized in Table III. The patients in the high CONUT group were significantly older (median: 71.9 years $v s .66 .9$ years, $p=0.0306$ ) and had higher clinical T stage (cT3 or more $v s$. cT2 or less: $54.6 \%$ vs. $25.8 \%, p=0.0194)$. In addition, the clinical $\mathrm{N}$ stage tended to be higher in the high CONUT group ( $\mathrm{cN} 1$ or more $v s . \mathrm{cN} 0$ : $22.8 \%$ vs. $7.5 \%, p=0.0513)$. Meanwhile, there were no significant differences in sex, smoking history, initial symptom, tumor grade, lymphovascular invasion (LVI), presence of hydronephrosis before $\mathrm{RC}$, or rate of neoadjuvant chemotherapy between the two groups (all, $p>0.05$ ).

Survival according to CONUT score. During the follow-up period [median: 21 (interquartile range: 4-61) months], local recurrence or distant metastasis was observed in 36 patients $(31.3 \%)$, and $23(20.0 \%)$ and $26(22.6 \%)$ patients died of cancer and any cause, respectively. Compared with the low CONUT group, the high CONUT group had significantly lower RFS (57.4\% vs. 61.1\%, $p=0.0292)$, CSS (48.1\% vs. $78.7 \%, p=0.0011)$, and OS $(55.0 \% v s .74 .6 \%, p=0.0210)$ at 5 years after RC (Figure 2).

Risk factors for survival. Univariate analyses for RFS, CSS, and OS showed that hydronephrosis, pT stage, pN stage, presence of LVI, and the CONUT score were significant factors (all, $p<0.05)$ (Table IV). Multivariate analyses of these factors further showed that the CONUT score was an independent factor for RFS $(\mathrm{HR}=3.55,95 \% \mathrm{CI}=1.41-8.50$, $p=0.0083), \mathrm{CSS}(\mathrm{HR}=6.01,95 \% \mathrm{CI}=2.23-16.0, p=0.0006)$, and $\mathrm{OS}(\mathrm{HR}=3.83,95 \% \mathrm{CI}=1.44-9.56, p=0.0085)$ (Table V). In addition, pT stage was also an independent factor for RFS $\quad(\mathrm{HR}=2.93, \quad 95 \% \mathrm{CI}=1.27-7.16, \quad p=0.0114), \quad \mathrm{CSS}$ $(\mathrm{HR}=4.34, \quad 95 \% \mathrm{CI}=1.41-15.6, \quad p=0.0094), \quad$ and $\mathrm{OS}$ $(\mathrm{HR}=3.21,95 \% \mathrm{CI}=1.18-9.89, p=0.0216)$, and $\mathrm{pN}$ stage was an independent factor for CSS $(\mathrm{HR}=2.70,95 \% \mathrm{CI}=0.97-6.90$, $p=0.0566$ ).

Complications according to the CONUT score. In total, 11 $(50.0 \%)$ and 56 patients $(60.2 \%)$ experienced any-grade postoperative complications in the high and low CONUT groups, respectively (Table VI). In addition, 3 and 17 patients experienced Grade $\geq$ III complications in the high and low CONUT groups, respectively (Table VI). There were no significant between-group differences in the rate of anygrade $(p=0.4724)$ and Grade $\geq$ III $(p=0.7607)$ complications. Grade IV or V complications did not occur. Meanwhile, the 
Table I. Calculation of the CONUT score.

\begin{tabular}{|c|c|c|c|c|}
\hline Parameter & None & Light & Moderate & Severe \\
\hline Serum albumin, $g / d l$ & $\geq 3.50$ & $3.00-3.49$ & $2.50-2.99$ & $<2.50$ \\
\hline Score & 0 & 2 & 4 & 6 \\
\hline $\begin{array}{l}\text { Total lymphocyte } \\
\text { count, } / \mathrm{mm}^{3}\end{array}$ & $\geq 1,600$ & $1,200-1,599$ & $800-1,199$ & $<800$ \\
\hline Score & 0 & 1 & 2 & 3 \\
\hline $\begin{array}{l}\text { Total cholesterol, } \\
\mathrm{mg} / \mathrm{dl}\end{array}$ & $\geq 180$ & $140-179$ & 100-139 & $<100$ \\
\hline Score & 0 & 1 & 2 & 3 \\
\hline
\end{tabular}

CONUT: Controlling nutritional status.

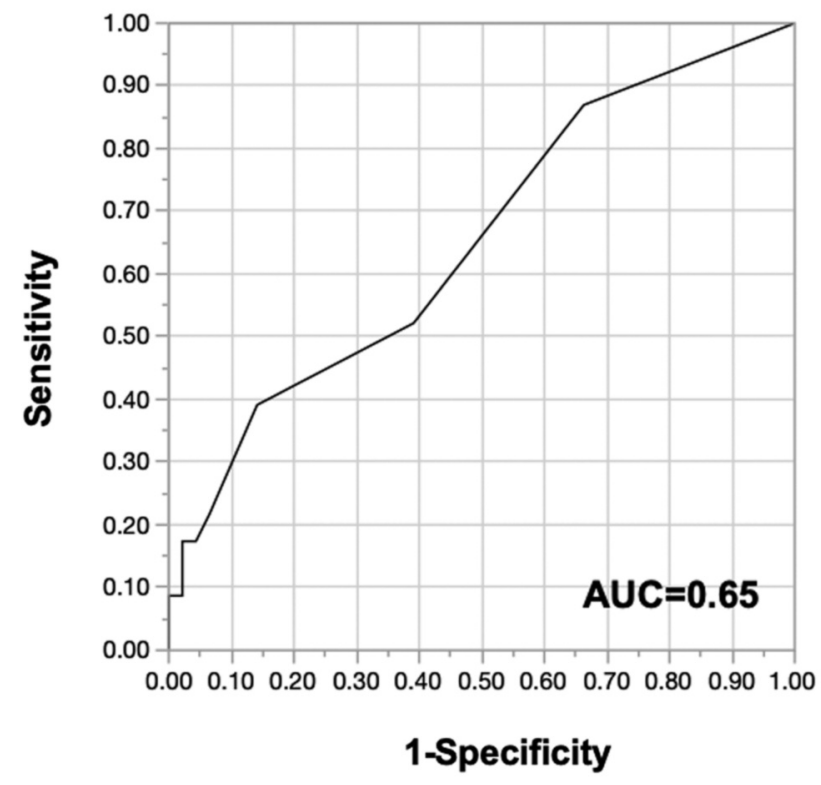

Figure 1. ROC curve for CONUT score. ROC curve predicted cancerspecific survival according to a preoperative CONUT score. According to the maximum Youden index method, the cut-off of CONUT score was determined at $3(A U C=0.65)$. ROC: Receiver operating characteristic; CONUT: controlling nutritional status; AUC: area under the curve.

duration of hospitalization after RC was significantly longer in the high CONUT group than that in the low CONUT group (median: 36.0 days vs. 28.4 days, $p=0.0458$; Table VI).

\section{Discussion}

This study revealed that RFS, CSS, and OS following RC for advanced $\mathrm{BC}$ were significantly shorter in patients with high CONUT score than in those with low CONUT score. Multivariate analysis further showed that the CONUT score was an independent factor for these survival outcomes. Moreover, a high CONUT score was significantly associated with a longer duration of postoperative hospitalization.
Table II. Number of patients according to the components of the CONUT score.

\begin{tabular}{lcc}
\hline Variable & High CONUT $(\mathrm{n}=22)$ & Low CONUT (n=93) \\
\hline CONUT score & & \\
0 & 0 & $34(36.6 \%)$ \\
1 & 0 & $33(35.5 \%)$ \\
2 & 0 & $26(28.0 \%)$ \\
3 & $11(50.0 \%)$ & 0 \\
4 & $3(13.6 \%)$ & 0 \\
5 & $2(9.1 \%)$ & 0 \\
6 & $2(9.1 \%)$ & 0 \\
7 & $2(9.1 \%)$ & 0 \\
8 & $1(4.5 \%)$ & 0 \\
9 & $1(4.5 \%)$ & 0 \\
Albumin score & & $92(98.9 \%)$ \\
0 & $10(45.5 \%)$ & $1(1.1 \%)$ \\
2 & $4(18.2 \%)$ & 0 \\
4 & $6(27.3 \%)$ & 0 \\
6 & $2(9.1 \%)$ & $45(48.4 \%)$ \\
Total lymphocyte score & & $32(34.4 \%)$ \\
0 & $3(13.6 \%)$ & $16(17.2 \%)$ \\
1 & $10(45.5 \%)$ & 0 \\
2 & $8(36.7 \%)$ & \\
3 & $1(4.5 \%)$ & 0 \\
Total cholesterol score & & \\
0 & $3(13.6 \%)$ & $(79.6 \%)$ \\
1 & $11(50.0 \%)$ & 0 \\
2 & $8(36.7 \%)$ & $(20.4 \%)$ \\
3 & 0 & 0 \\
\hline
\end{tabular}

CONUT: Controlling nutritional status.

These findings suggested that the CONUT score was significantly associated with oncological outcomes including survival and tolerability of advanced BC patients undergoing $\mathrm{RC}$.

The association between the CONUT score and prognosis in urological cancers has been previously investigated. In renal cell carcinoma, the CONUT score was significantly associated with survival, and this prognostic impact was superior to other nutritional factors such as the Prognostic Nutritional Index (23). The CONUT score was also an independent prognostic factor in prostate cancer with oligometastasis (24). Further, the CONUT score has recently been reported to have a prognostic impact in urothelial carcinoma. Specifically, the CONUT score was associated with PFS and OS in advanced urothelial carcinoma including BC patients who underwent multimodal treatment including surgery, platinum-based systemic chemotherapy, and radiation therapy (25). However, in that study, only $56 \%$ of the overall cohort had advanced BC. In contrast, we evaluated an exclusive cohort of advanced $\mathrm{BC}$ and found that the CONUT score has a prognostic impact in advanced BC.

In the past, it has also been reported that postoperative pancreatic fistula, one of the complications after 
Table III. Patient characteristics according to the CONUT score.

\begin{tabular}{|c|c|c|c|}
\hline Variable & $\begin{array}{l}\text { High CONUT } \\
\quad(\mathrm{n}=22)\end{array}$ & $\begin{array}{c}\text { Low CONUT } \\
(\mathrm{n}=93)\end{array}$ & $p$-Value \\
\hline $\begin{array}{l}\text { Age, y (continuous } \\
\text { variable) }\end{array}$ & $71.9 \pm 9.21$ & $66.9 \pm 9.59$ & 0.0306 \\
\hline $\begin{array}{l}\text { Age, y (categorical } \\
\text { classification) } \geq 70 \\
\text { (ref. }<70 \text { ) }\end{array}$ & $13(59.1 \%)$ & $41(44.1 \%)$ & 0.2400 \\
\hline \multicolumn{4}{|l|}{ Gender } \\
\hline $\begin{array}{l}\text { Male (ref. female) } \\
\text { Smoking }\end{array}$ & \multicolumn{2}{|c|}{ Smoking } & 0.4104 \\
\hline With (ref. without) & $6(27.3 \%)$ & $42(45.2 \%)$ & 0.2573 \\
\hline Initial symptom & & & $0.7581^{*}$ \\
\hline Gloss hematuria & $15(68.2 \%)$ & $52(55.9 \%)$ & \\
\hline Dysuria & $2(9.1 \%)$ & $16(17.2 \%)$ & \\
\hline No symptom & $4(17.4 \%)$ & $10(10.8 \%)$ & \\
\hline Others & $1(9.1 \%)$ & $15(16.1 \%)$ & \\
\hline cT stage & & & $0.0194 * *$ \\
\hline $\mathrm{cTa} / \mathrm{cTis}$ & 0 & $11(11.8 \%)$ & \\
\hline cT1 & $4(17.4 \%)$ & $14(15.1 \%)$ & \\
\hline cT2 & $7(30.4 \%)$ & $44(47.3 \%)$ & \\
\hline cT3 & $7(30.4 \%)$ & $9(9.7 \%)$ & \\
\hline cT4 & $5(21.7 \%)$ & $10(10.8 \%)$ & \\
\hline $\mathrm{cN}$ stage & & & $0.0513^{* * *}$ \\
\hline $\mathrm{cNO}$ & $17(77.3 \%)$ & $86(92.5 \%)$ & \\
\hline $\mathrm{cN} 1$ & $3(13.6 \%)$ & $3(3.2 \%)$ & \\
\hline $\mathrm{cN} 2$ & $1(4.5 \%)$ & $4(4.3 \%)$ & \\
\hline $\mathrm{cN} 3$ & $1(4.5 \%)$ & 0 & \\
\hline \multicolumn{4}{|l|}{ Tumor grade } \\
\hline High (ref. low) & $16(72.7 \%)$ & $80(86.0 \%)$ & 0.1835 \\
\hline \multicolumn{4}{|l|}{ LVI } \\
\hline With (ref. without) & $12(54.5 \%)$ & $42(45.2 \%)$ & 0.4816 \\
\hline \multicolumn{4}{|l|}{ Number of tumors } \\
\hline Multiple (ref. single) & $15(68.2 \%)$ & $51(54.3 \%)$ & 0.3391 \\
\hline \multicolumn{4}{|l|}{ Hydronephrosis } \\
\hline With (ref. without) & $6(27.3 \%)$ & $26(28.0 \%)$ & 0.9486 \\
\hline \multicolumn{4}{|c|}{ Neo-adjuvant chemotherapy } \\
\hline With (ref. without) & $11(50.0 \%)$ & $41(44.1 \%)$ & 0.6412 \\
\hline Urinary diversion & & & 0.1546 \\
\hline Ileal conduit & $10(45.5 \%)$ & $46(49.5 \%)$ & \\
\hline Neo bladder & $5(22.7 \%)$ & $35(37.6 \%)$ & \\
\hline Others & $7(31.8 \%)$ & $9(9.7 \%)$ & \\
\hline
\end{tabular}

CONUT: Controlling nutritional status; CI: confidence interval; LVI: lymphovascular invasion. *There is no significant difference between with or without any symptom ("Others" included to group with symptom). The $p$-value was calculated by comparing these two groups using Fisher's two-sided test. **The patients in the high CONUT group had higher clinical T stage. The $p$-value was determined using Fisher's two-sided test in the comparison between the two groups (cT3 or more $v s$. cT2 or less). ***The $p$-value was the value derived from the comparison between $\mathrm{cN} 0$ and $\mathrm{cN} 1$ or more.

pancreaticoduodenectomy for pancreatic cancer, occurred more frequently in patients with poor nutritional status (26). Interestingly, in the present study, although we did not find any difference in the rate or grade of complications according to the CONUT score, the duration of a

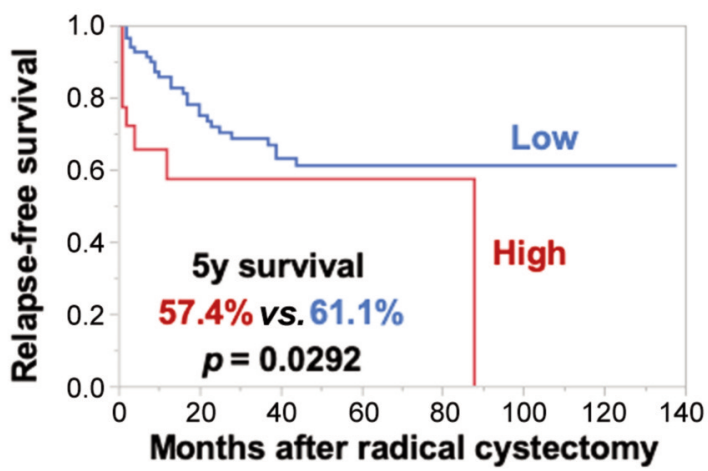

b

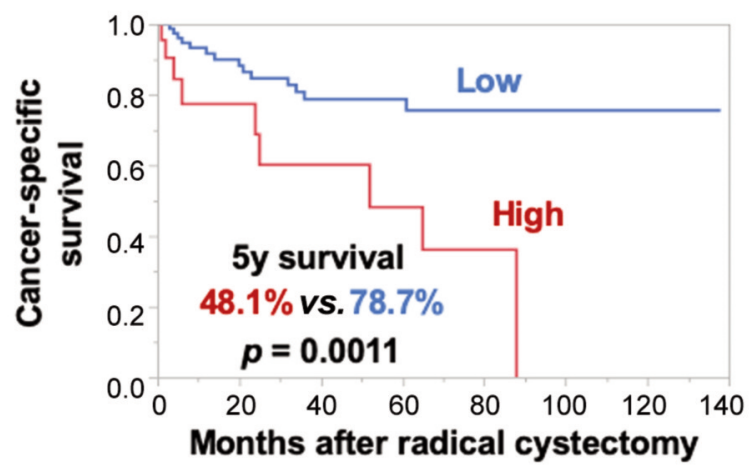

C

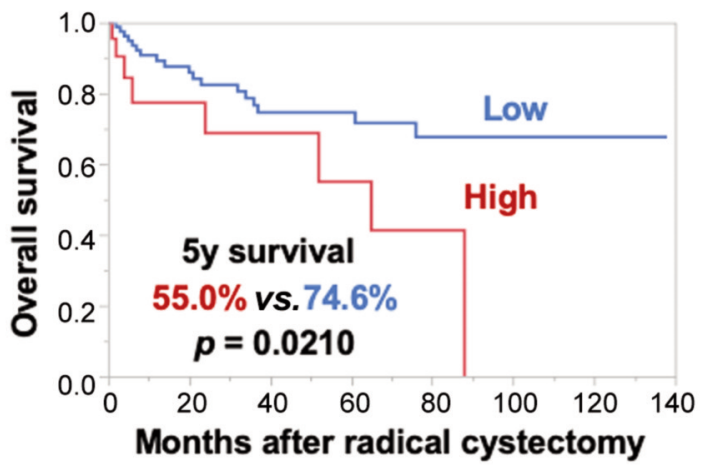

Figure 2. Relapse-free survival, cancer-specific survival, and overall survival according to the CONUT score. Kaplan-Meier curves for (a) relapse-free survival, (b) cancer-specific survival, and (c) overall survival following radical cystectomy for advanced bladder cancer according to the CONUT score. CONUT: Controlling nutritional status.

postoperative hospitalization was longer in the high CONUT group. This might suggest that there is a delay of recovery of the general condition from invasive surgery among patients with low nutritional status irrespective of complication development. To the best of our knowledge, 
Table IV. Univariate analysis for risk factors for RFS, CSS and OS after radical cystectomy for advanced bladder cancer.

\begin{tabular}{|c|c|c|c|c|c|c|}
\hline Variable & $\begin{array}{c}\text { RFS } \\
\text { HR }(95 \% \mathrm{CI})\end{array}$ & $p$-Value & $\begin{array}{c}\text { CSS } \\
\text { HR }(95 \% \mathrm{CI})\end{array}$ & $p$-Value & $\begin{array}{c}\text { OS } \\
\text { HR }(95 \% \mathrm{CI})\end{array}$ & $p$-Value \\
\hline \multicolumn{7}{|l|}{ Gender } \\
\hline Male (ref. female) & $1.09(0.52-2.57)$ & 0.8304 & $1.45(0.54-5.01)$ & 0.4823 & $1.27(0.52-3.81)$ & 0.6211 \\
\hline \multicolumn{7}{|l|}{ Age, years } \\
\hline$\geq 70($ ref. $<70)$ & $1.13(0.57-2.20)$ & 0.7186 & $1.62(0.71-3.81)$ & 0.2492 & $1.97(0.90-4.50)$ & 0.0886 \\
\hline \multicolumn{7}{|l|}{ Smoking } \\
\hline With (ref. without) & $0.74(0.37-1.44)$ & 0.3708 & $0.72(0.30-1.63)$ & 0.4309 & $0.82(0.37-1.78)$ & 0.6186 \\
\hline \multicolumn{7}{|l|}{ Symptom } \\
\hline With (ref. without) & $1.22(0.49-2.64)$ & 0.6428 & $0.57(0.24-1.58)$ & 0.2607 & $0.67(0.29-1.86)$ & 0.4230 \\
\hline \multicolumn{7}{|l|}{ Number of tumors } \\
\hline Multiple (ref. single) & $0.67(0.34-1.32)$ & 0.2442 & $0.60(0.26-1.38)$ & 0.2251 & $0.78(0.36-1.71)$ & 0.5219 \\
\hline \multicolumn{7}{|l|}{ Hydronephrosis } \\
\hline With (ref. without) & $2.48(1.23-4.86)$ & 0.0125 & $3.44(1.49-7.91)$ & 0.0046 & $3.85(1.76-8.46)$ & 0.0010 \\
\hline \multicolumn{7}{|c|}{ Neo-adjuvant chemotherapy } \\
\hline With (ref. without) & $0.54(0.26-1.09)$ & 0.0856 & $0.54(0.16-1.09)$ & 0.0776 & $0.39(0.14-0.91)$ & 0.0294 \\
\hline \multicolumn{7}{|l|}{ pT Stage } \\
\hline$\geq$ pT3 $($ ref. $\leq$ pT2) & $2.80(1.42-5-84)$ & 0.0029 & $4.08(1.69-11.3)$ & 0.0014 & $3.91(1.71-10.0)$ & 0.0010 \\
\hline \multicolumn{7}{|l|}{ pN Stage } \\
\hline$\geq \mathrm{pN} 1($ ref. N0) & $2.56(1.13-5.31)$ & 0.0260 & $3.21(1.22-7.59)$ & 0.0198 & $2.63(1.02-6.04)$ & 0.0454 \\
\hline \multicolumn{7}{|l|}{ LVI } \\
\hline With (ref. without) & $2.27(1.16-4.57)$ & 0.0169 & $4.11(1.70-11.4)$ & 0.0014 & $3.91(1.71-10.0)$ & 0.0010 \\
\hline \multicolumn{7}{|l|}{ CONUT score } \\
\hline$\geq 3($ ref. $<3)$ & $2.27(1.00-4.69)$ & 0.0354 & $3.71(1.54-8.49)$ & 0.0046 & $2.58(1.06-5.78)$ & 0.0385 \\
\hline
\end{tabular}

RFS: Relapse-free survival; CSS: cancer-specific survival; OS: overall survival; HR: hazard ratio; CI: confidence interval; LVI: lymphovascular invasion; CONUT: controlling nutritional status.

Table V. Multivariate analysis for risk factors for RFS, CSS, and OS after radical cystectomy for advanced bladder cancer.

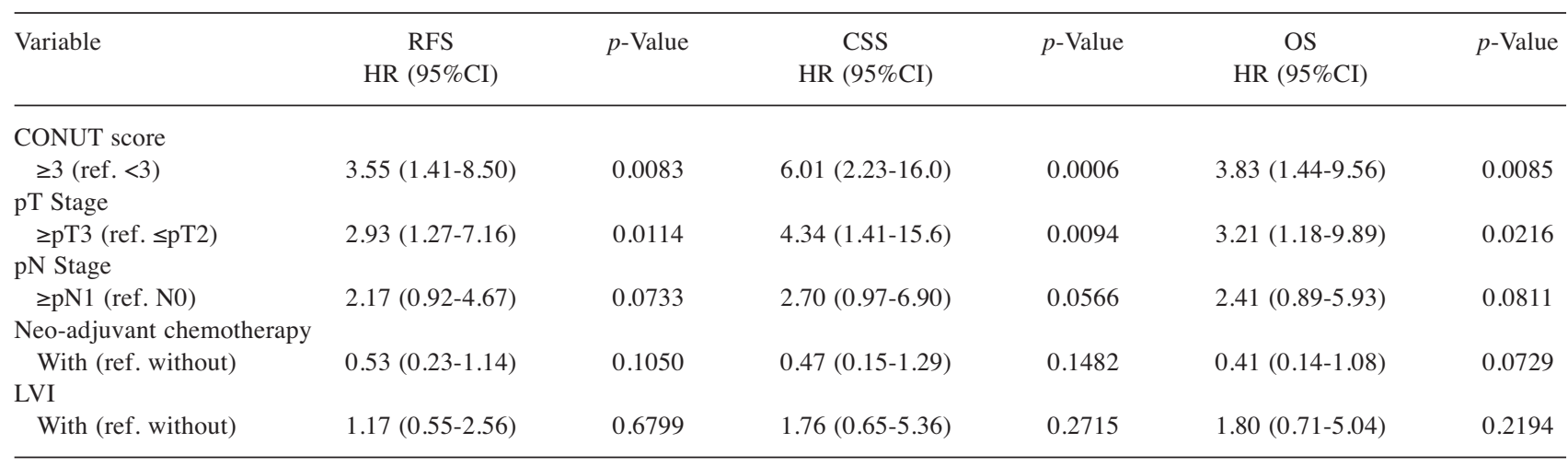

RFS: Relapse-free survival; CSS: cancer-specific survival; OS: overall survival; HR: hazard ratio; CI: confidence interval; LVI: lymphovascular invasion; CONUT: controlling nutritional status.

this was the first study indicating the possibility of CONUT score as a predictive factor of tolerability for invasive surgery in urologic cancers.

The CONUT score is determined based on the serum albumin concentration, total lymphocyte count, and total cholesterol concentration. The serum albumin level is a major component of serum total protein and reflects nutrition and inflammation status (27). Lymphocytes generally inhibit or attenuate cancer cell growth and migration and promote the apoptosis of cancer cells (28). As for cholesterol, its role in cancer development, invasiveness, or aggressiveness remains unclear. However, serum cholesterol levels have been reported as a predictive or prognostic factor in cancer (29-31). Moreover, altered levels and mutations of genes involved in the cholesterol homeostasis pathways have been identified in cancer cells (32). These include increases in gene copy numbers, up-regulation of cholesterol synthesis gene expression, enhanced cholesterol import by low-density 
Table VI. Perioperative outcomes according to CONUT score.

\begin{tabular}{|c|c|c|c|}
\hline $\begin{array}{l}\text { Variable } \\
\qquad(\mathrm{n}=22)\end{array}$ & $\begin{array}{l}\text { High CONUT } \\
\qquad(\mathrm{n}=93)\end{array}$ & Low CONUT & $p$-Value \\
\hline \multicolumn{4}{|l|}{ Complications } \\
\hline Incidence (all Grade) & $11(50.0 \%)$ & $56 *(60.2 \%)$ & 0.4724 \\
\hline Incidence (Grade $\geq \mathrm{III}$ ) & $3(13.6 \%)$ & $17(18.3 \%)$ & 0.7607 \\
\hline \multicolumn{4}{|l|}{ Grade I } \\
\hline Wound infection & $1(4.5 \%)$ & $6(6.5 \%)$ & \\
\hline Dehiscence & 0 & $5(5.4 \%)$ & \\
\hline Ileus & $2(9.1 \%)$ & $6(6.5 \%)$ & \\
\hline Catheter infection & 0 & $1(1.1 \%)$ & \\
\hline Urinary retention & 0 & $1(1.1 \%)$ & \\
\hline Anastomosis failure & 0 & $3(3.2 \%)$ & \\
\hline Radial nerve palsy & 0 & $1(1.1 \%)$ & \\
\hline \multicolumn{4}{|l|}{ Grade II } \\
\hline Wound infection & $1(4.5 \%)$ & $5(5.4 \%)$ & \\
\hline Dehiscence & $1(4.5 \%)$ & $2(2.2 \%)$ & \\
\hline Ileus & 0 & $2(2.2 \%)$ & \\
\hline Pyelonephritis & $1(4.5 \%)$ & $10(10.8 \%)$ & \\
\hline Pelvic abscess & $2(9.1 \%)$ & $2(2.2 \%)$ & \\
\hline Thrombosis & 0 & $1(1.1 \%)$ & \\
\hline Lymph node abscess & 0 & $1(1.1 \%)$ & \\
\hline \multicolumn{4}{|l|}{ Grade IIIa } \\
\hline Wound infection & 0 & $2(2.2 \%)$ & \\
\hline Dehiscence & 0 & $1(1.1 \%)$ & \\
\hline Ileus & $1(4.5 \%)$ & $3(3.2 \%)$ & \\
\hline Lymphatic fistula & 0 & $1(1.1 \%)$ & \\
\hline Hydronephrosis & 0 & $1(1.1 \%)$ & \\
\hline Stenosis of anastomosis & 0 & $2(2.2 \%)$ & \\
\hline Anastomosis failure & 0 & $1(1.1 \%)$ & \\
\hline \multicolumn{4}{|l|}{ Grade IIIb } \\
\hline Ileus & 0 & $1(1.1 \%)$ & \\
\hline Pelvic abscess & $1(4.5 \%)$ & 0 & \\
\hline Rectal injury & 0 & $1(1.1 \%)$ & \\
\hline Genital necrosis & 0 & $1(1.1 \%)$ & \\
\hline Cystorectal fistula & $1(4.5 \%)$ & 0 & \\
\hline Intestinal perforation & 0 & $1(1.1 \%)$ & \\
\hline Leak of neobladder & 0 & $1(1.1 \%)$ & \\
\hline Obturator nerve injury & 0 & $1(1.1 \%)$ & \\
\hline $\begin{array}{l}\text { Number of days hospitalized- } \\
\text { after surgery }\end{array}$ & $36.0 \pm 20.4$ & $28.4 \pm 18.6$ & 0.0458 \\
\hline
\end{tabular}

CONUT: Controlling nutritional status. ${ }^{*}$ Cases that resulted in multiple complications were counted as one.

lipoprotein receptors, and decreased transport of cholesterol, which promote increased cellular cholesterol levels to aid cancer cell proliferation (33).

This study has several limitations. First, because this study was retrospectively conducted using a small sample size in a single center, the findings were affected by unavoidable bias. Therefore, external validations with a large sample size in multiple institutions are warranted to confirm our findings. Second, because the CONUT score was calculated at the time of post neoadjuvant chemotherapy, the patients' nutritional status was expected to be affected to some extent. Further studies are needed to validate our findings.

\section{Conclusion}

The CONUT score was significantly associated with oncological outcomes including survival and tolerability following RC in advanced BC. Further, a higher CONUT score was associated with a longer duration of postoperative hospitalization. Considering that the CONUT score can be easily assessed using blood samples obtained in daily clinical practice, it can be a less invasive and effective predictor.

\section{Conflicts of Interest}

This research did not receive any specific grant from funding agencies in the public, commercial, or not-for-profit sectors.

\section{Authors' Contributions}

Yuki Nemoto, Tsunenori Kondo, Hiroki Ishihara, Toshio Takagi, Hideki Ishida, and Kazunari Tanabe were involved in study design and data interpretation. Yuki Nemoto, Hiroki Ishihara were involved in data analysis. All Authors critically revised the manuscript, approved the manuscript to be published, and agree to be accountable for all aspects of the work in ensuring that questions related to the accuracy or integrity of any part of the work are appropriately investigated and resolved.

\section{Acknowledgements}

The Authors thank Ms. Nobuko Hata (Department of Urology, Tokyo Women's Medical University) for her secretarial work.

\section{References}

1 Arends J, Bachmann P, Baracos V, Barthelemy N, Bertz H, Bozzetti F, Fearon K, Hütterer E, Isenring E, Kaasa S, Krznaric Z, Laird B, Larsson M, Laviano A, Mühlebach S, Muscaritoli M, Oldervoll L, Ravasco P, Solheim T, Strasser F, de van der Schueren M and Preiser JC: Espen guidelines on nutrition in cancer patients. Clin Nutr 36(1): 11-48, 2017. PMID: 12490959. DOI: $10.1038 /$ nature 01322

2 Coussens LM and Werb Z: Inflammation and cancer. Nature 420(6917): 860-867, 2002. PMID: 12490959. DOI: 10.1038/ nature 01322

3 McMillan DC: Systemic inflammation, nutritional status and survival in patients with cancer. Curr Opin Clin Nutr Metab Care 12(3): 223-226, 2009. PMID: 19318937. DOI: 10.1097/ MCO.0b013e32832a7902

4 Alberici Pastore C, Paiva Orlandi S and González MC: Association between an inflammatory-nutritional index and nutritional status in cancer patients. Nutr Hosp 28(1): 188-193, 2013. PMID: 23808449. DOI: 10.3305/nh.2013.28.1.6167

5 Jagoe RT, Goodship TH and Gibson GJ: The influence of nutritional status on complications after operations for lung cancer. Ann Thorac Surg 71(3): 936-943, 2001. PMID: 11269477. DOI: $10.1016 / \mathrm{s} 0003-4975(00) 02006-3$

6 Rey-Ferro M, Castaño R, Orozco O, Serna A and Moreno A: Nutritional and immunologic evaluation of patients with gastric 
cancer before and after surgery. Nutrition 13(10): 878-881, 1997. PMID: 9357024. DOI: 10.1016/s0899-9007(97)00269-4

7 Barret M, Malka D, Aparicio T, Dalban C, Locher C, Sabate JM, Louafi S, Mansourbakht T, Bonnetain F, Attar A and Taieb J: Nutritional status affects treatment tolerability and survival in metastatic colorectal cancer patients: Results of an ageo prospective multicenter study. Oncology 81(5-6): 395-402, 2011. PMID: 22269999. DOI: 10.1159/000335478

8 Iseki Y, Shibutani M, Maeda K, Nagahara H, Ohtani H, Sugano K, Ikeya T, Muguruma K, Tanaka H, Toyokawa T, Sakurai K and Hirakawa K: Impact of the preoperative controlling nutritional status (conut) score on the survival after curative surgery for colorectal cancer. PLoS One 10(7): e0132488, 2015. PMID: 26147805. DOI: 10.1371/journal.pone. 0132488

9 Kang HW, Seo SP, Kim WT, Yun SJ, Lee SC, Kim WJ, Hwang EC, Kang SH, Hong SH, Chung J, Kwon TG, Hoe Kim H, Kwak C, Byun SS, Kim YJ and Group KKRCC: Prognostic impact of nutritional status assessed by the controlling nutritional status (conut) score in patients with surgically treated renal cell carcinoma. Nutr Cancer 70(6): 886-894, 2018. PMID: 30235010. DOI: 10.1080/01635581.2018.1490448

10 Akamine T, Toyokawa G, Matsubara T, Kozuma Y, Haratake N, Takamori S, Katsura M, Takada K, Shoji F, Okamoto T and Maehara Y: Significance of the preoperative conut score in predicting postoperative disease-free and overall survival in patients with lung adenocarcinoma with obstructive lung disease. Anticancer Res 37(5): 2735-2742, 2017. PMID: 28476853. DOI: 10.21873/anticanres.11625

11 Kirkali Z, Chan T, Manoharan M, Algaba F, Busch C, Cheng L, Kiemeney L, Kriegmair M, Montironi R, Murphy WM, Sesterhenn IA, Tachibana M and Weider J: Bladder cancer: Epidemiology, staging and grading, and diagnosis. Urology 66(6 Suppl 1): 4-34, 2005. PMID: 16399414. DOI: 10.1016/j.urology. 2005.07.062

12 Tan WS, Lamb BW and Kelly JD: Complications of radical cystectomy and orthotopic reconstruction. Adv Urol 2015: 323157, 2015. PMID: 26697063. DOI: 10.1155/2015/323157

13 Gregg JR, Cookson MS, Phillips S, Salem S, Chang SS, Clark PE, Davis R, Stimson CJ, Aghazadeh M, Smith JA and Barocas DA: Effect of preoperative nutritional deficiency on mortality after radical cystectomy for bladder cancer. J Urol 185(1): 9096, 2011. PMID: 21074802. DOI: 10.1016/j.juro.2010.09.021

14 Kimura S, D' Andrea D, Soria F, Foerster B, Abufaraj M, Vartolomei MD, Iwata T, Karakiewicz PI, Rink M, Gust KM, Egawa S and Shariat SF: Prognostic value of modified glasgow prognostic score in non-muscle-invasive bladder cancer. Urol Oncol 37(3): 179.e119-179.e128, 2019. PMID: 30580906. DOI: 10.1016/j.urolonc.2018.11.005

15 Miyake M, Morizawa Y, Hori S, Marugami N, Iida K, Ohnishi K, Gotoh D, Tatsumi Y, Nakai Y, Inoue T, Anai S, Torimoto K, Aoki K, Tanaka N, Shimada K, Konishi N and Fujimoto K: Integrative assessment of pretreatment inflammation-, nutrition-, and musclebased prognostic markers in patients with muscle-invasive bladder cancer undergoing radical cystectomy. Oncology 93(4): 259-269, 2017. PMID: 28647740. DOI: 10.1159/000477405

16 Peng D, Gong YQ, Hao H, He ZS, Li XS, Zhang CJ and Zhou LQ: Preoperative prognostic nutritional index is a significant predictor of survival with bladder cancer after radical cystectomy: A retrospective study. BMC Cancer 17(1): 391, 2017. PMID: 28578683. DOI: 10.1186/s12885-017-3372-8
17 Ishihara H, Kondo T, Yoshida K, Omae K, Takagi T, Iizuka J and Tanabe K: Preoperative controlling nutritional status (conut) score as a novel predictive biomarker of survival in patients with localized urothelial carcinoma of the upper urinary tract treated with radical nephroureterectomy. Urol Oncol 35(9): 539.e539539.e516, 2017. PMID: 28499734. DOI: 10.1016/j.urolonc. 2017.04.012

18 Ishihara H, Kondo T, Omae K, Takagi T, Iizuka J, Kobayashi H, Hashimoto $\mathrm{Y}$ and Tanabe K: Sarcopenia predicts survival outcomes among patients with urothelial carcinoma of the upper urinary tract undergoing radical nephroureterectomy: A retrospective multi-institution study. Int J Clin Oncol 22(1): 136144, 2017. PMID: 27422388. DOI: 10.1007/s10147-016-1021-x

19 Fluss R, Faraggi D and Reiser B: Estimation of the youden index and its associated cutoff point. Biom J 47(4): 458-472, 2005. PMID: 16161804. DOI: 10.1002/bimj.200410135

20 Sobin LH, Gospodarowicz MK and Wittekind C: TNM classification of malignant tumours. John Wiley \& Sons, 2011.

21 Ignacio de Ulíbarri J, González-Madroño A, de Villar NG, González P, González B, Mancha A, Rodríguez F and Fernández G: Conut: A tool for controlling nutritional status. First validation in a hospital population. Nutr Hosp 20(1): 38-45, 2005. PMID: 15762418 .

22 Dindo D, Demartines N and Clavien PA: Classification of surgical complications: A new proposal with evaluation in a cohort of 6336 patients and results of a survey. Ann Surg 240(2): 205-213, 2004. PMID: 15273542. DOI: 10.1097/01.sla. 0000133083.54934.ae

23 Zheng Y, Bao L, Wang W, Wang Q, Pan Y and Gao X: Prognostic impact of the controlling nutritional status score following curative nephrectomy for patients with renal cell carcinoma. Medicine (Baltimore) 97(49): e13409, 2018. PMID: 30544418. DOI: 10.1097/MD.0000000000013409

24 Zhang W, Wu Y, Zhang Z, Guo Y, Wang R, Wang L, Mao S, Zhang $\mathrm{J}$ and Yao X: Controlling nutritional status score: A new prognostic indicator for patients with oligometastatic prostate cancer. Curr Probl Cancer 43(5): 461-470, 2019. PMID: 30910226. DOI: 10.1016/j.currproblcancer.2019.02.001

25 Suzuki H, Ito M, Takemura K, Nakanishi Y, Kataoka M, Sakamoto K, Tobisu KI and Koga F: Prognostic significance of the controlling nutritional status (conut) score in advanced urothelial carcinoma patients. Urol Oncol, 2019. PMID: 31864938. DOI: 10.1016/j.urolonc.2019.10.014

26 Utsumi M, Aoki H, Nagahisa S, Nishimura S, Une Y, Kimura Y, Taniguchi F, Arata T, Katsuda K and Tanakaya K: Preoperative nutritional assessment using the controlling nutritional status score to predict pancreatic fistula after pancreaticoduodenectomy. In Vivo 34(4): 1931-1939, 2020. PMID: 32606165. DOI: 10.21873/ invivo. 11990

27 McMillan DC, Watson WS, O'Gorman P, Preston T, Scott HR and McArdle CS: Albumin concentrations are primarily determined by the body cell mass and the systemic inflammatory response in cancer patients with weight loss. Nutr Cancer 39(2): 210-213, 2001. PMID: 11759282. DOI: 10.1207/ S15327914nc392_8

28 Mantovani A, Allavena P, Sica A and Balkwill F: Cancer-related inflammation. Nature 454(7203): 436-444, 2008. PMID: 18650914. DOI: 10.1038/nature07205

29 Cengiz O, Kocer B, Sürmeli S, Santicky MJ and Soran A: Are pretreatment serum albumin and cholesterol levels prognostic 
tools in patients with colorectal carcinoma? Med Sci Monit 12(6): CR240-247, 2006. PMID: 16733481.

30 Kang HW, Seo SP, Kim WT, Yun SJ, Lee SC, Kim WJ, Hwang EC, Kang SH, Hong SH, Chung J, Kwon TG, Kim HH, Kwak C, Byun SS, Kim YJ and group KKRCC: Low preoperative serum cholesterol level is associated with aggressive pathologic features and poor cancer-specific survival in patients with surgically treated renal cell carcinoma. Int J Clin Oncol 23(1): 142-150, 2018. PMID: 31961621. DOI: 10.1590/S16775538.IBJU.2019.0560

31 Li B, Huang D, Zheng H, Cai Q, Guo Z and Wang S: Preoperative serum total cholesterol is a predictor of prognosis in patients with renal cell carcinoma: A meta- analysis of observational studies. Int Braz J Urol 46(2): 158-168, 2020. PMID: 31961621. DOI: 10.1590/S1677-5538.IBJU.2019.0560
32 Murai T: Cholesterol lowering: Role in cancer prevention and treatment. Biol Chem 396(1): 1-11, 2015. PMID: 25205720. DOI: $10.1515 / \mathrm{hsz}-2014-0194$

33 Kuzu OF, Noory MA and Robertson GP: The role of cholesterol in cancer. Cancer Res 76(8): 2063-2070, 2016. PMID: 27197250. DOI: 10.1158/0008-5472.CAN-15-2613

Received December 19, 2020

Revised January 2, 2021

Accepted January 4, 2021 